\title{
Erratum to: You Support Diversity, But Are You Ethical? Examining the Interactive Effects of Diversity and Ethical Climate Perceptions on Turnover Intentions
}

\author{
Robert W. Stewart
}

Published online: 15 June 2011

(C) Springer Science+Business Media B.V. 2011

Erratum to: Journal of Business Ethics

$$
\text { (2011) 99:453-465 }
$$

DOI 10.1007/s10551-010-0663-2

'You Support Diversity, But Are You Ethical? Examining the Interactive Effects of Diversity and Ethical Climate Perceptions on Turnover Intentions' has been republished with DOI 10.1007/s10551-010-0697-5. In the republication the correct author group: Robert W. Stewart, Sabrina
D. Volpone, Derek R. Avery and Patrick McKay has been published.

The original article was erroneously published in the Journal of Business Ethics, volume 99, issue 3, March (III), 2011. The republication of the above mentioned article will be published in the Journal of Business Ethics, volume 100, issue 4, June (I), 2011.

The publisher wishes to apologize to the authors for any inconvenience caused.

The online version of the original article can be found under doi:10.1007/s10551-010-0663-2.

R. W. Stewart $(\bowtie)$

Department of Psychology, University of Houston, Houston,

TX, USA

e-mail: rwstew@gmail.com 